\title{
You are just being emotional! Testimonial injustice and folk-psychological attributions
}

Rodrigo Díaz ${ }^{\mathrm{a}}$ \& Manuel Almagro ${ }^{\mathrm{b}}$

${ }^{a}$ Institute of Philosophy, University of Bern. Langassstrasse 49a, 3012 Bern. https://orcid.org/0000-0002-1709-5806

${ }^{\mathrm{b}}$ Department of Philosophy 1, University of Granada. Campus de la Cartuja, Universidad de Granada, Calle del Prof. Clavera, s/n, 18011 Granada. https://orcid.org/0000-0003-1647-9995

This is a post-peer-review, pre-copyedit version of an article published in Synthese. The final authenticated version is available online at: http://dx.doi.org/10.1007/s11229-019-02429-w

\section{Acknowledgements}

We are thankful to Melanie Altanian, Víctor Fernández Castro, Neftalí Villanueva Fernández, and two reviewers for this journal for their valuable comments on early drafts of the paper. This work was funded by the Swiss National Science Foundation (research project 100012_169484), the Spanish Ministry of Economy (Project FFI2016-80088-P, FPI Predoctoral Fellow BES-2017- 079933), and the FiloLab Excellence Unit.

\begin{abstract}
Testimonial injustices occur when individuals from particular social groups are systematically and persistently given less credibility in their claims merely because of their group identity. Recent "pluralistic" approaches to folk psychology, by taking into account the role of stereotypes in how we understand others, have the power to explain how and why cases of testimonial injustice occur. If how we make sense of others' behavior depends on assumptions about how individuals from certain groups think and act, this can explain why speakers are given different degrees of credibility depending on their group identity. For example, if people
\end{abstract}


assume that women are more emotional than men (and they consider that emotionality hinders credibility), they will systematically give less credibility to women's claims. This explanation involves three empirical claims: (1) People assume that women are more emotional than men, (2) people assume that emotionality hinders credibility, and (3) people give less credibility to women's claims. While extant studies provide some support for (1) and (2), no study to date has directly tested (3). In two different studies, we tested all these three claims. The results from both studies provide support for (2), as we found significant negative correlations between emotionality and credibility attributions. However, in contrast to what some accounts of folk psychology posit, we did not find any significant difference in people's attributions of emotionality and credibility towards women versus men speakers. We hope that our studies here pave the way for further empirical studies testing the phenomenon of testimonial injustice in a context-sensitive way, in order to have a better understanding of the conditions in which testimonial injustices are likely to happen.

\section{Introduction}

In the last few years, a wealth of theoretical and empirical literature has been devoted to studying the diversity of social and structural injustices suffered by oppressed groups. This literature has shown that belonging to an unprivileged social group increases the degree of exposure to injustices of various kinds. A much-discussed issue nowadays in ethics and social epistemology, but also in the public sphere, is that individuals from socially disadvantaged groups (such as women or African-Americans) are given less credibility in their claims than equally competent individuals coming from other social groups. In other words, that nonepistemic factors such as race and gender influence how much we value other people's claims. Paradigmatic examples of this phenomenon, known as testimonial injustice (Fricker, 2007), involve real-life scenarios such as testifying at a trial or trying to make one's voice heard at a company meeting.

Recently, discussions of testimonial injustice have also entered the literature on social cognition and folk psychology (Burroughs and Tollefsen, 2016; Munroe, 2016; Buckwalter, 2018; Spaulding, 2018a, 2018b; Saegert, 2019). Most philosophical and psychological discussions regarding how we understand others are concerned with our attributions of beliefs and desires in order to predict and explain behavior. This literature, however, has recently taken a turn. So- 
called pluralistic approaches to folk psychology broaden the scope of traditional approaches in order to consider the attribution of psychological features other than beliefs and desires, e.g. character traits. By broadening the scope of folk-psychological attributions, pluralistic approaches are in a good position to account for the influence of stereotypes in our understanding of others, and explain phenomena such as testimonial injustice.

Stereotypes are to be understood as assumptions regarding the character traits of people in certain groups. In other words, our assumptions regarding how people in those groups think and act. Stereotypes can thus explain how and why we take individuals in disadvantaged groups less seriously. From a pluralistic approach to folk psychology, the phenomenon of testimonial injustice could be explained in the following way: We give less credibility to certain individuals because we make sense of their verbal behavior in the light of negative stereotypes.

While there is a wealth of literature on stereotypes in social psychology, there is a surprising gap when it comes to studies directly investigating the phenomenon of testimonial injustice. Thus, philosophers interested in these issues have to support their claims with empirical studies that are not well suited to support their claims. Here, we will present a first attempt to fill this gap by presenting the results of a series of philosophically informed empirical studies on gender stereotypes in folk-psychological attributions and credibility judgments. In particular, we will investigate whether assumptions regarding women's emotionality influence attributions of credibility.

\section{Testimonial Injustice}

A substantial body of literature in social epistemology is devoted to studying the unfair treatment that some socially unprivileged groups receive in the contexts of our communicative, interpretative, and knowledge exchange practices (Fricker, 2007; Kidd, Medina and Pohlhaus, 2017; Medina, 2013: Kukla, 2014; Dotson, 2011; Ayala, 2016; Peet, 2015).

The notion of epistemic injustice, as characterized by Fricker, points to cases in which a person tries to share knowledge and yet finds it difficult to do so because of the prejudices and stereotypes associated with the socially disadvantaged group to which she belongs (Fricker, 2007; see also Kidd, Medina and Pohlhaus, 2017). Epistemic injustice fundamentally consists 
of a wrong done to someone in her epistemic autonomy or capacity as a knower, that is, her ability to take part autonomously in social practices of acquiring and communicating knowledge. However, according to Fricker, not all situations of these sorts are instances of epistemic injustice. In order to count as an epistemic injustice, the wrong done must be caused by identity prejudices (prejudices about groups in virtue of their culture, gender, sexual orientation, etc.), and must be systematic (affect several different social dimensions: political, economic, legal, etc.) and persistent (Fricker 2007: 4, 27-29). There are at least two ways in which the capacity of a subject as a knower can be undermined. Someone can be epistemically harmed (1) if she cannot understand her own experience or (2) if she cannot convey knowledge to others by telling them. The former is known as hermeneutical injustice, while the latter receives the name of testimonial injustice.

Hermeneutical injustices arise when a subject that belongs to an oppressed group suffers an asymmetrical cognitive disadvantage for understanding her own experience in virtue of a structural identity prejudice. The characteristic feature of hermeneutical injustice is that there is "a gap in collective interpretive resources [that] puts someone at an unfair disadvantage when it comes to making sense of their social experience" (Fricker 2007: 1). Note that the unfair disadvantage suffered must be systematic and persistent to be an epistemic injustice. A wellknown example of hermeneutical injustice discussed by Fricker is that of suffering sexual harassment before having the concept. The lack of the concept of sexual harassment makes it much more difficult for victims to understand and communicate their own experiences, favoring the harassers' interpretation. Thus, this kind of injustice is caused by a conceptual gap due to the exclusion of individuals in disadvantaged groups from various practices through which meaningful, shared concepts are created.

Testimonial injustices, on the other hand, occur when a subject that belongs to an oppressed group systematically and persistently receives a credibility deficit in virtue of an identity prejudice. The idea is that speakers from certain groups are accorded insufficient credibility in their claims just because of their social identity (Fricker, 2007: 1). This injustice may occur gradually, that is, the hearer may completely disbelieve or ignore what the subject says or simply give her less credibility than she deserves, but all these possible situations count as cases of testimonial injustice. A well-known example of testimonial injustice that Fricker discusses in her book is a scene from The Talented Mr. Ripley in which Marge Sherwood, after expressing her suspicion that Ripley killed her partner, receives the following response from Herbert 
Greenleaf: 'Marge, there's female intuition, and then there are facts' (Fricker, 2007: 9). In this case, Herbert dismisses Marge's claims on the basis of the stereotype that women are "not sufficiently rational", but instead have an "emotional" or "intuitive" character.

There are other notions closely related to notions of epistemic injustice which, however, have different extensions. The notions of discursive injustice (Kukla, 2014) or speech injustice (Ayala, 2016), for instance, point to cases where a person tries to carry out a particular speech act and her words are systematically interpreted as carrying out a different speech act due to the stereotypes associated with the social group to which the speaker belongs. The notion of interpretative injustice points to cases in which a person makes a claim and the meaning of her words is distorted due to her belonging to a socially disadvantaged group (Peet, 2015). For example, in 2014, the Supreme Court of Spain announced its open days with a poster depicting a naked woman and a slogan with the words 'get to know her'. A group of women magistrates released a statement denouncing the sexism and inappropriateness of the poster. The news appeared in a newspaper under the headline 'A naked woman to advertise the open days of the Supreme Court angers the magistrates.' This constitutes an injustice. The magistrates pointed out the inappropriateness of the poster and yet were interpreted as angry, as if they were expressing their anger rather than asserting something (see Ayala, 2018). As this example shows, discursive and interpretative injustice can be seen as a breed of testimonial injustice. The interpretation of the magistrates' claims as a different speech act than the one they were trying to perform is a way to undermine the credibility or epistemic status of their claims. In the next section, we will see how recent accounts of folk psychology enable us to explain cases of testimonial injustice such as these ones.

\section{Stereotypes and Folk Psychology}

In her 2008 article "It's in your nature: a pluralistic approach to folk psychology", Kristin Andrews argues that our folk psychological practices for predicting and explaining behavior are not reduced to the attribution of propositional attitudes. While discussion around folk psychology mostly revolves around the attribution of beliefs and desires, Andrews points out the importance of character trait attributions for predicting and explaining behavior. For example, we predict that generous people will behave altruistically, and we explain their acts of giving in terms of their generosity. But we do not expect egoistic people to exhibit altruistic 
behavior, and we will probably explain their acts of giving as driven by hidden egoistic intentions. Most importantly, Andrews claims that character trait attribution cannot be reduced to belief/desire attribution, as both show a different ontogenetic development and they are empirically dissociable. For example, we can explain someone's behavior in terms of her selfcenteredness without attributing her the belief nor the desire to act in a self-centered way.

Other recent accounts of folk psychology have also taken into account the role of character trait attributions in how we understand others (for a review, see Spaulding, 2018b). These accounts are sometimes known, following Andrews's terminology, as pluralistic approaches. Different authors have given different explanations of how character trait attributions feature in our folk psychology. However, for our purposes here, the relevant point is that they do take into account character trait attributions, rather than how they incorporate this feature into their theories.

Taking into account the role character trait attributions in our folk psychology is of special relevance because it can explain the role of social categorization in our behavioral predictions and explanations. The social category to which a person belongs influences what we expect from her and how we understand her behavior. We do not expect a one-year-old to show the same behavioral patterns as an adult. We assume that infants and adults have different character traits. Thus, in the same context, we will attribute different psychological features depending on the age of the target. For example, a baby crying at a funeral probably wants food, while an adult crying at a funeral is probably grieving. Some of the character traits that we automatically associate to people according to their social group, however, are not as innocent as the babyadult divide. As we have seen in the previous section, other categorizations of people have important ethical consequences. In particular, we presented two examples of how assumptions about women's emotionality lead to epistemic harm. Because women are considered emotional, their claims are interpreted in distorted ways (as in the case of the Supreme Court magistrates in Spain) and are not considered worthy of credibility (as in the scene from The Talented Mr. Ripley). This is one of the ways in which testimonial injustice can occur.

In a recent book, Shannon Spaulding (2018a) makes the abovementioned connection between (pluralistic) folk psychological attributions and epistemic injustice, and incorporates this into a comprehensive account of mindreading called Model Theory. In a nutshell, Model Theory posits that folk psychology works by using models, i.e., simple representations of the general structure and properties of other minds. These models include knowledge about how individual 
persons think and act (among other things), but also stereotypes and social biases. For example, we have models about how specific individuals that are close to us think and act, but also models about how people of a specific age, gender, or race think and act. Among other contextual and personal factors, the model that we (implicitly or explicitly) use to "mindread" someone will depend on our spontaneous categorization of the target person into a specific group. And, importantly, the model will include assumptions regarding the psychological features of people in this group. Thus, the mental states and character traits that we attribute to others to predict and explain their behavior will vary depending on the group identity of the target. This way, Model Theory offers a way of operationalizing the mechanisms and conditions under which cases of testimonial injustice will take place. Spontaneously categorizing a person into an oppressed group lead us to make sense of her behavior in the light of negative stereotypes, which will in turn make us downgrade the credibility of this person. This seems like a sound explanation. But do we have direct evidence supporting this explanation?

\section{Stereotypes and Credibility: previous studies}

In order to back up her claims regarding spontaneous categorization and testimonial injustice, Spaulding builds on extant social psychological work on stereotypes, in particular, work on the Stereotype Content Model (SCM). Studies within the SCM paradigm have showed that, across different cultures, women are considered to be less competent than men (Cuddy et al., 2009; Eckes, 2002; Fiske et al., 2002). Other studies investigating people's competence assessments of men vs. women subjects corroborate these findings (Brescoll and Uhlmann, 2008; Eaton et al., 2019; Foschi, 1994, 1996). Although the extent to which women are considered less competent varies from study to study (Cuddy et al., 2004), and within groups of women (with businesswomen usually considered as more competent than homemakers, Fiske et al., 1999), studies consistently find this gender stereotype. Research within the SCM paradigm, however, does not aim to directly support claims regarding testimonial injustice towards women, but rather to demonstrate that stereotypes cluster around two dimensions: competence and warmth. In consequence, using it for the former purposes faces certain limitations.

Studies within the SCM paradigm use a similar methodology based on questionnaires. To assess competence stereotypes, participants are asked about how "competent", "capable", or 
"intelligent" (but also "confident", "competitive", or "efficient")' are members of different groups, as viewed by society. The relation between these assessments and credibility attributions, however, is not completely straightforward. As Spaulding notes, context is of special relevance when making sense of people's behavior. One can be regarded as generally incompetent or even unintelligent but nevertheless be regarded as credible in many aspects, e.g., one's personal first-hand experience. In other words, there is a gap between competence and credibility attributions, and therefore we cannot just assume that low competence stereotypes will necessarily lead to credibility deficits. While the SCM paradigm provides a wealth of evidence showing that people generally consider women to be less competent than men, it does not provide conclusive evidence regarding the connection between these stereotypes and credibility deficits.

Yet another possible source of empirical support to claims regarding testimonial injustice is the literature on implicit bias. For example, research has shown that many people all across the world implicitly associate men with science/math and women with arts/humanities (Zitelny et al., 2017). This research could explain some specific cases of testimonial injustice. In particular, people's implicit association of women with non-scientific careers could explain why women in science are given less credibility than their male peers. However, as it has already been noted by Jennifer Saul (2017), implicit bias might occur without testimonial injustice. One could implicitly associate women with non-scientific careers without ever failing to give credibility to the claims of a female scholar. That is, one can have an (epistemically-relevant) implicit bias without ever doing any testimonial injustice. This worry is increased by the fact that the connection between implicit bias and discriminatory behavior is nowadays the subject of huge controversy. Looking at meta-analyses of studies investigating the relationship between implicit biases and discriminatory behavior, one can observe that there is a disagreement regarding the size of the effect of implicit bias on discriminatory behavior (Cameron et al., 2012; Forscher et al., 2019; Kurdi et al., 2018; Oswald et al., 2013), as well as regarding the societal relevance of the meta-analytical results (Banaji et al., 2015; Oswald et al., 2015). Furthermore, this literature has focused on implicit biases regarding ethnicity, and investigated discriminatory behaviors other than testimonial injustices (Carlsson and Agerström, 2016). Similar to what happened in the case of SCM studies, while there is a wealth of evidence showing that people have negative

\footnotetext{
${ }^{1}$ This constitutes a first worry with regards to the relation between competence and credibility attributions, as these terms do not clearly refer to the epistemic capacities of members of the target group. Being regarded as, e.g. competitive, is probably unrelated to being regarded as credible.
} 
implicit biases towards women, we could not find any study investigating the connection between those implicit biases and testimonial injustices in particular.

Finally, we would like to highlight some studies which do provide evidence suggesting that women are given less credibility than their male peers. These studies investigate the phenomenon of workplace incivility. Workplace incivility refers to "low-intensity deviant behavior with ambiguous intent to harm the target, in violation of workplace norms for mutual respect." (Andersson and Pearson, 1999). Cortina and colleagues (Cortina et al., 2001, 2013) have conducted a series of studies in which they show that women are more likely to suffer workplace incivility than men. In these studies, they asked participants how frequently during the past year they were in a situation in which their supervisors or co-workers performed certain behaviors. Among these behaviors, there is a clear case of testimonial injustice: "(your supervisor or co-worker) Doubted your judgment on a matter over which you had responsibility." The rest of behaviors in the questionnaire are not cases of testimonial injustice, e.g. "(your supervisor or co-worker) Yelled, shouted, or swore at you." Nevertheless, as the different items in the questionnaire are highly related to each other, it is likely that there were significant differences in the extent that women vs. men reported having been doubted in their judgment. But once again we face some problems, as these studies were not designed with the aim of supporting claims about credibility deficits towards women.

To sum up, there is a wealth of empirical research showing that women are the target of different kinds of negative stereotypes and discriminatory behaviors. However, to our knowledge, no study to date has directly tested the phenomenon of testimonial injustice. This entails certain limitations when it comes to using the available studies to support claims regarding credibility deficits for women vs men speakers. This is an important area of research and more work needs to be done. In this paper, we try to fill this apparent gap in the empirical literature. Building on paradigmatic examples in the testimonial injustice literature and pluralistic approaches to folk psychology, we will test a very specific way in which gender stereotypes can influence credibility attributions.

\section{Stereotypes and Credibility: new studies}


In our present investigation, we would like to build on Spaulding's Model Theory of mindreading to empirically investigate the phenomenon of testimonial injustice. Note, however, that other accounts of folk psychology that consider the role of stereotypes in folkpsychological attributions would make similar predictions. Building on Spaulding's Model Theory, at least some cases of testimonial injustice towards women (like the ones we saw in Section 2) could be understood in the following way:

(1) People assume that women are more emotional than men.

(2) People assume that emotionality hinders credibility.

(3) Women are given less credibility than men.

In other words, women are given less credibility because we make sense of their behavior in light of "emotionality" stereotypes, and we consider emotionality to be an epistemically biasing factor. The social psychological literature provides some empirical support for both (1) (Plant et al., 2000) and (2) (Zammuner, 2000). This, in turn, provides support for (3). However, to our knowledge, no systematic empirical study has provided direct evidence in favor of this claim yet.

\subsection{Study 1}

In this study, we aim to empirically test one of the ways in which cases of testimonial injustice can occur, namely, that when women make assertions (when they try to provide information on some issue), they are instead interpreted as expressing feelings. To interpret someone as expressing feelings when trying to make a claim about something is not only a way to give her less credibility than she deserves and therefore a way in which a testimonial injustice can be committed; it can also be a way of committing a discursive or interpretative injustice: it can be argued that her speech act failed and that the meaning of her words was distorted. The unjust situations that these notions point to can occur in many different ways: interpreting a woman as expressing feelings when she tries to assert something is just one more way for one of these unjust situations to take place. 
In order to test this, we designed vignettes in which speakers make claims that aim to describe a particular situation, and manipulated the gender of the speaker. Thus, each vignette has two versions, which are exactly the same except for one factor: the speaker is either a man or a woman. We depicted claims that merely point to aspects of the situation, but chose situations that personally affect the speaker, so they can also be interpreted as expressions of feelings. This allows us to test whether (1) a claim is more likely to be interpreted as an expression of feelings when the speaker is a woman, (2) interpreting a claim as an expression of feelings leads to downgrading its credibility, and (3) women are given less credibility in their claims.

\subsubsection{Method}

120 participants were recruited to Amazon Mechanical Turk and completed the survey for a monetary payment. 13 participants were excluded as they guessed one of the experimental hypotheses, leaving a sample of 107 participants (61 male, 51 female, 1 other, Mean age = 38.38, Standard Deviation $=13.90$, age range 20-87). Post-hoc power analyses using G*Power showed that we had $82 \%$ power to detect an effect of $d=.5$. Participants were randomly assigned to the Woman $(\mathrm{N}=53)$ or Man $(\mathrm{N}=52)$ condition of one of our 4 vignettes (see Appendix). ${ }^{2}$ For example, one of the vignettes (similar to the real case used by Ayala, 2018; see Section 2) was as follows (between brackets the wording for the Man condition):

The members of the Supreme Court have chosen an image of a naked woman as a poster to announce an event. Lisa (Mark), a female (male) magistrate, sends a statement to the Supreme Court saying the following:

"This image could be appropriate for an artistic exhibition, but not in this context. The figure of a naked woman is no longer the way society represents justice since centuries ago."

Participants first answered the question "Is Lisa (Mark) describing the situation or expressing her (his) feelings?" on a scale from 1 ("Just describing the situation") to 7 ("Just expressing her/his feelings"), with the midpoint (4) labeled as "Both to the same extent". This allows us to test to what extent participants consider the speaker's claims as expressions of feelings (in contrast to assertions about the situation). The higher the ratings, the more the protagonist's

\footnotetext{
${ }^{2}$ With more than 50 participants per condition, we meet the recommended minimums for social psychology studies (Simmons et al., 2018)
} 
claim is taken to be an expression of feelings. From now on, we will refer to this question as the Emotionality question.

Afterwards, they answered the question "How much credibility would you give to Lisa (Mark)?" on a scale from 1 ("No credibility at all") to 7 ("A lot of credibility"), with the midpoint (4) labeled as "In between". Ratings in this question indicate how much credibility our participants give to the protagonist of the vignette. We will refer to this question as the Credibility question.

At the end of the survey, participants were asked to write down which hypotheses they think were being tested in our study, and whether these thoughts affected their responses. This question served as a control question. Participants who mentioned gender or a relation between emotion and credibility were excluded from the analysis to avoid demand effects and social desirability biases. This allows us to be sure that participants' responses are not guided by their awareness of what is being tested.

\subsubsection{Results}

Emotionality ratings for Women $($ Mean $=4.19, S D=1.81)$ and Men $($ Mean $=4.87, S D=1.80)$ speakers were not significantly different, $t(105)=1.071, p=.287, d=.376 .{ }^{3}$

We found a significant negative correlation between Emotionality and Credibility ratings, $r=$ $.306, p=.001$. There was a tendency such as the more the speakers' claims are considered to be expressing their feelings (instead of just describing the situation), the less credibility was given to them (see Figure 1).

Finally, Credibility ratings for Women $($ Mean $=4.87, S D=1.64)$ and Men $($ Mean $=4.78, S D=$ 1.71) speakers were not significantly different, $t(107)=.278, p=.90, d=.054 .^{4}$

\footnotetext{
${ }^{3}$ We used independent sample t-tests for differences between groups and bivariate correlations for the relation between emotionality and credibility.

${ }^{4}$ Exploratory ANOVA analyses found no interaction between gender of the speaker and vignette used in neither credibility nor emotionality ratings (all $p s>.05$ ). This suggests that our results are not due to the influence of uncontrolled factors that varied from vignette to vignette.
} 


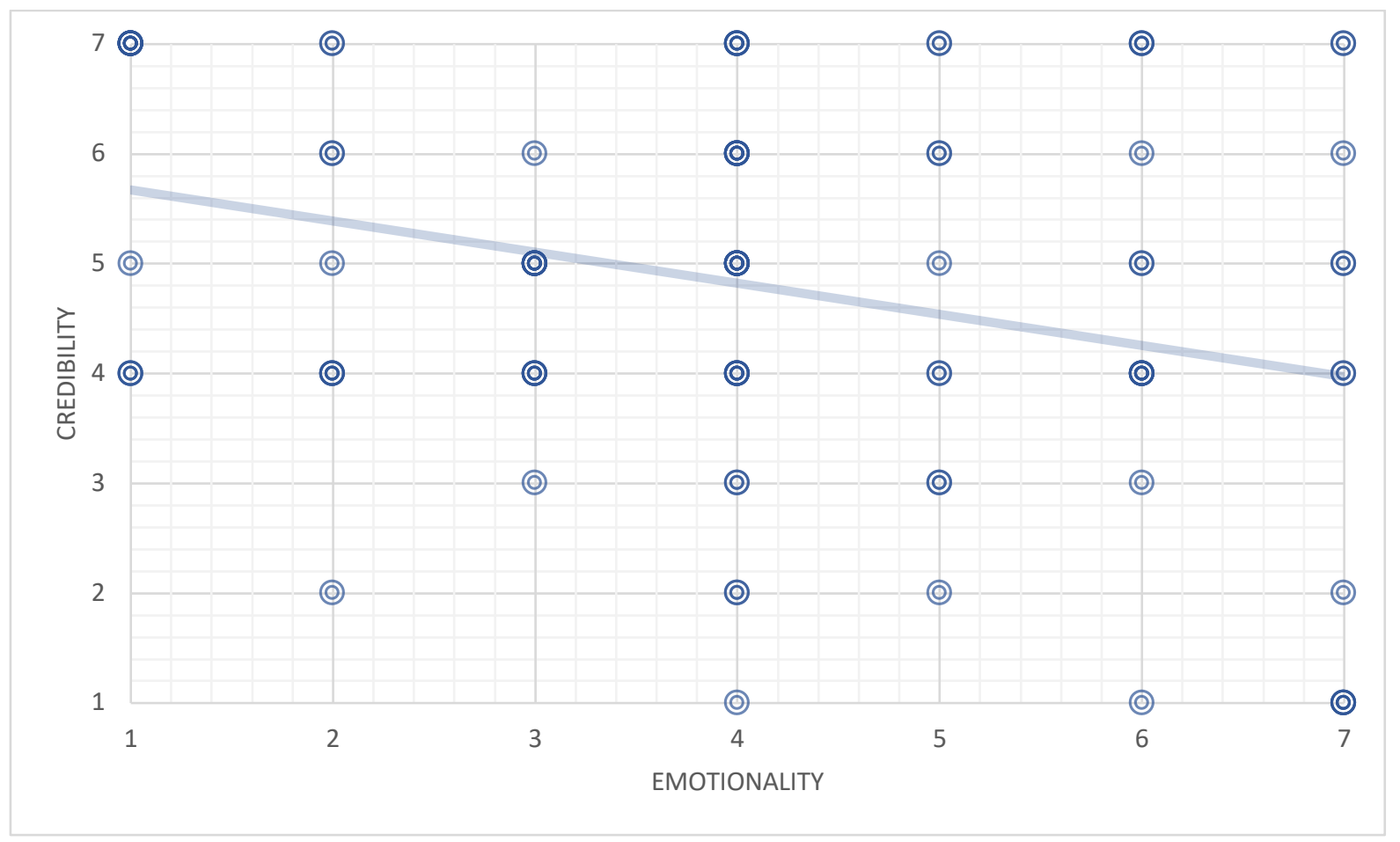

Figure 1. Relation between Emotionality and Credibility ratings in Study 1.

\subsubsection{Discussion}

Consistent with the idea that emotionality hinders credibility, we found that the more the speaker's claim is taken to be an expression of feelings (instead of an assertion), the less credibility is given to the speaker. However, the gender of the speaker in the vignette did not affect participants' responses. We did not find any significant difference in Emotionality or Credibility attributions as a function of the gender of the speaker.

At this point, one could be happy that our participants did not show any stereotypes regarding women's and men's emotionality, nor were epistemically unjust towards women. However, one could also point out some aspects of our design that could be problematic. The first worry concerns the Emotionality question. Assessing a speech act as expressive or assertive might be a somewhat complicated task for lay people. Furthermore, the vignettes we used might be interpreted as cases that trigger anger. Anger is an emotion that is commonly associated to men, or at least it is an emotion that can have a different meaning depending on whether it is attributed to a woman or a man (see Traister, 2018), which could explain why we did not find differences in Emotionality attributions towards women and men speakers. The second worry concerns the Credibility question. In the vignettes that we used, participants only have one piece of 
information: the one provided by the protagonist of the vignette. In the absence of contradictory information, participants might be drawn to always give credibility to the protagonist. Furthermore, the credibility question was perhaps too general, what could also feed on this problem. In our second study, we introduced a series of modifications in our design in order to address these worries.

\subsection{Study 2}

In this second study, we tried to overcome some limitations of our first study by making some important changes in the experimental design. First, we introduced changes in the Emotionality and Credibility questions. We also recruited twice as many participants, in order to have enough statistical power to detect small effects. Finally, we modified the previously used vignettes by introducing a sentence presenting conflicting evidence (stating that other people have a different judgment of the situation) and introduced new vignettes that try to depict paradigmatic cases of testimonial injustice. These changes are detailed in the next section. The hypotheses we are trying to test are the same as in the first study: (1) women are perceived as more emotional than men, (2) emotionality is considered to hinder credibility, and (3) women are given less credibility than men.

\subsubsection{Method}

250 participants were recruited to Amazon Mechanical Turk and completed the survey for a monetary payment. 37 participants were excluded as they guessed one of the experimental hypotheses, leaving a sample of 223 participants (115 male, 107 female, 1 other, Mean age = $35.10, S D=10.52$, age range 20-68). Post-hoc power analyses using $\mathrm{G}^{*}$ Power showed that we had $98 \%$ power to detect an effect of $d=.5$. Participants were randomly assigned to the Woman $(\mathrm{N}=97)$ or Man $(\mathrm{N}=126)$ condition of one of our 4 vignettes (see Appendix). We introduced two new vignettes. One of the new vignettes depicted Fricker's paradigmatic example of testimonial injustice from the screenplay The Talented Mr. Ripley, and read as follows (between brackets the wording for the Man condition):

Susan (Daniel) is a 30-year-old woman (man). Two weeks ago, her husband (his wife) mysteriously disappeared. Today, Susan (Daniel) receives a call from the police office. They communicate that they have not found her husband (his wife), but they have clear indications that he (she) committed suicide. Susan (Daniel) 
replies:

"That is just false. It's completely impossible. He (She) would never commit suicide. He (She) was a very happy man (woman)."

Participants then answered the Emotionality and Credibility questions. The order of presentation was counterbalanced. For the Emotionality question, participants answered "Is Susan (Daniel) being emotional?" on a scale from 1 ("Not at all") to 7 ("Extremely"), with the midpoint (4) labeled as "In between". Recent research suggests that gender stereotypes regarding emotion are not necessarily about women showing more emotion but rather about women's emotions being attributed to their character ("she is emotional") rather than to the situation ("she is having a bad day") (Barrett and Bliss-Moreau, 2009). Thus, we think that this measure of Emotionality could be more adequate than the one we used in Study 1 to detect perceived differences based on gender.

In the Credibility question, participants answered "If you were to judge whether this was a case of suicide, how much would you take into account Susan's (Daniel's) claims?" on a scale from 1 ("Not at all") to 7 ("Very much"), with the midpoint (4) labeled as "In between". This question also has putative advantages in contrast to the Credibility question used in Study 1. First, it refers specifically to the matter that the speaker is making a claim about. Secondly, it measures credibility in a more indirect way. While people might be concerned about not giving credibility to a person, they might be more willing to say that they would not take much into account someone's claims regarding a specific issue (especially considering that there are conflicting claims by other people).

As in Study 1, at the end of the survey participants were asked to write down which hypotheses they think were being tested in our study, and whether these thoughts affected their responses. Participants who guessed one of the hypotheses were excluded from the analysis to avoid demand effects and social desirability biases.

\subsubsection{Results}


Emotionality ratings for Women $($ Mean $=3.69, S D=1.92)$ and Men $($ Mean $=3.79, S D=1.76)$ speakers were not significantly different, $t(221)=.417, p=.677, d=.054$ (See figure 2). ${ }^{5}$

We found a significant negative correlation between Emotionality and Credibility ratings, $r=-$ $.153, p=.022$. There was a tendency such as the more the speaker is considered to be emotional, the less their claims were taken into account.

Finally, Credibility ratings for Women $($ Mean $=4.91, S D=1.17)$ and Men $($ Mean $=5.05, S D=$ 1.42) speakers were not significantly different, $t(221)=.789, p=.431, d=.108$ (see Figure 2$){ }^{6}$

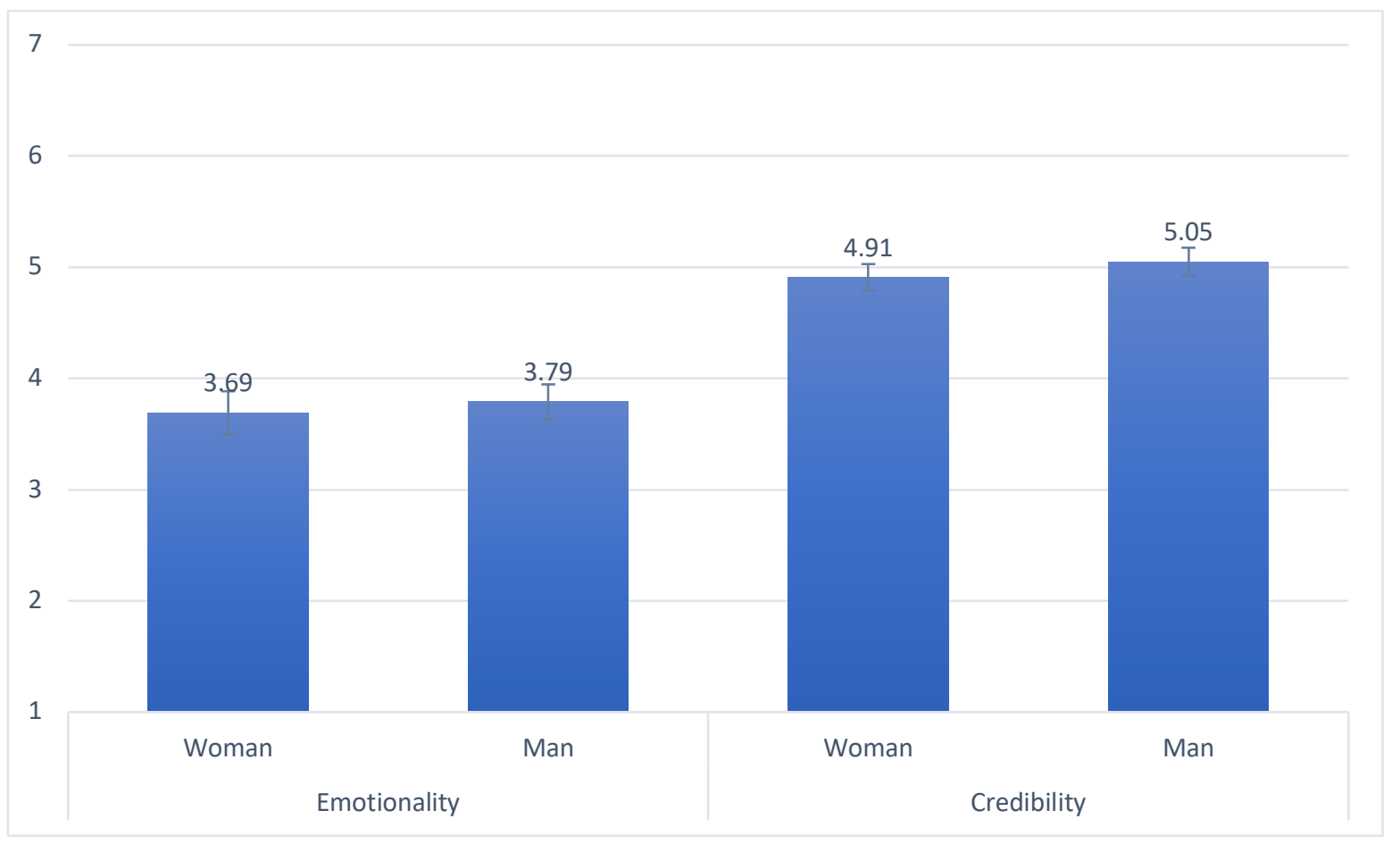

Figure 2. Emotionality and Credibility ratings by condition (woman speaker, man speaker) in Study 2. Error bars represent the Standard Error of the mean.

\subsubsection{Discussion}

In Study 2, we replicated the results of Study 1 using a bigger sample size and an improved experimental design. We found that higher Emotionality ratings were related to lower

\footnotetext{
${ }^{5}$ We used independent sample t-tests for differences between groups and bivariate correlations for the relation between emotionality and credibility.

${ }^{6}$ Exploratory ANOVA analyses found no interaction between gender of the speaker and vignette used in neither credibility nor emotionality ratings (all $p s>.05$ ). This suggests that our results are not due to the influence of uncontrolled factors that varied from vignette to vignette.
} 
Credibility ratings. However, we found no significant differences in Emotionality nor Credibility attributions to women and men speakers.

\section{General discussion}

We started this paper by presenting the phenomenon known as testimonial injustice, according to which individuals from certain social groups are given less credibility in their claims just because of their group membership. Afterwards, we discussed how pluralistic approaches to folk psychology are well suited to explain this phenomenon. By taking into account the role of social categorization and stereotyping in folk-psychological attributions, pluralistic approaches to folk psychology such as Spaulding's Model theory have explanatory power to account for cases of testimonial injustice. However, claims about how people attribute psychological features to others are straightforward empirical claims. We found that there is a gap in the empirical literature when it comes to supporting claims about testimonial injustice towards women. We analyzed and decomposed examples of testimonial injustice towards women in three claims:

(1) Women are considered to be more emotional than men.

(2) Emotionality is considered to hinder credibility.

(3) Women are considered to be less credible than men.

Using an experimental-philosophical approach, we operationalized and tested these claims in two vignette studies. In these studies, participants were presented with cases in which speakers make claims regarding a situation that personally affects them. We manipulated the gender of the speaker (woman, man) maintaining all the other features of the story constant, and analyzed whether this manipulation influenced participants' attributions of emotionality (1) and credibility (3), and whether those two were related to each other (2). In two different studies using slightly different operationalizations, we could only find evidence for the claim that emotionality is considered to hinder credibility (2). In both studies, emotionality attributions were negatively correlated to credibility attributions. In other words, the more participants considered speakers to be emotional, the less credibility they attributed to those speakers. However, we found no significant differences between folk-psychological attributions of emotionality and credibility to men and women speakers. 
As we have seen, Model Theory and other pluralistic accounts of folk psychology posit that social categorization and stereotyping play an important role in our practices of understanding others. According to Model Theory, the social identity of the target makes a difference in how we make sense of the target's behavior. Contrary to this, the results of our studies showed no such differences. However, Model Theory also establishes that stereotypes of social biases play a role in cases in which our goal is to make efficient rather than accurate folk-psychological attributions. Thus, one could argue that our studies did not find an effect of the target's social identity because participants in our studies were aiming at making accurate attributions of emotionality and credibility. We believe, however, that this was hardly the case. The main motivation of participants in our study is arguably the monetary payment they obtain for completing the survey. This payment was always the same, effort was not rewarded. Plus, participants in our studies were explicitly told that we are interested in their intuitive responses. Thus, it is unlikely that participants were aiming at accuracy when completing the survey.

Taking into account the contrast between, on the one hand, the wealth of evidence regarding sexist biases and, on the other hand, our failure to find evidence of testimonial injustice towards women, one might question whether our experimental design was adequate to measure what it was intended to be measured. First, one might worry that our questions regarding emotionality, especially in Study 1, were too abstract to be properly understood by participants, and so participants tended to respond to the least risky medium of the scale (Hetherington and Rudolph, 2015: 18-19). Second, it might be that our credibility questions were too direct. If this is the case, participants could have been able to detect that they are being asked about their gender biases, and so they did not respond from their own intuitions but trying not to look sexist. However, there is some evidence suggesting that our measures were adequate. In both studies, we found a significant negative correlation between emotionality and credibility attributions, which suggest that participants responses to both questions are meaningful and not merely the product of a performance error. Furthermore, we asked participants to guess which the hypotheses of our studies were, and excluded from the analyses all participants who mentioned gender, women, sexism, and related terms. This suggests that participants' responses are not due to social desirability biases. It is important to note, however, that our design does not exclude the possibility that gender-bias-blocking processes operate at a sub-personal level, outside of participants' awareness. This is an interesting possibility that could explain why the participants in our studies did not attribute emotionality and credibility differentially to women and men, and should be further investigated in the future. 
If the abovementioned considerations hold, and the null results found here are not due to flaws in our experimental design, should we conclude that testimonial injustice is not real? The answer to this question is a clear no. The fact that, on average, the participants in our studies did not attribute less credibility to women than men does not mean that there are no cases in which women are given less credibility than their male peers. But why are women given less credibility than men in some cases, but in other cases (like in the studies here) they are not? The results of our studies suggest that the phenomenon of testimonial injustice is context-dependent. The only non-epistemic factor that was systematically manipulated in our study was the social identity of the target (women vs. men). It is possible that other non-epistemic factors are also relevant for testimonial injustices to arise. If this is the case, it makes sense to analyze under which conditions we did not find any evidence of credibility deficits to women. A first consideration regards the population we tested: Amazon Mechanical Turk (AMT) workers in the United States. Although US AMT workers are a more heterogenous group than college students or other typical convenience samples used in the social sciences, and also more attentive (Hauser and Schwarz, 2015), they are not representative of the whole US population (Stewart et al., 2017). Thus, it could be that demographic groups not well-represented in our sample are more prone to commit testimonial injustices. Second, and most importantly, we should look at the specific vignettes we used. In our vignettes, we focused on cases in which the speaker is personally involved in the issue at hand, and they are thus likely to be emotionally involved. We chose to use this type of cases because paradigmatic examples in the testimonial injustice literature, such as the scene from The Talented Mr. Ripley or the real case involving the Spanish Supreme Court magistrates, take this form. However, it might be that these cases are not the type of cases in which women speakers are more likely to suffer credibility deficits. Alternatively, credibility deficits in emotional cases might not arise when the emotion is clearly explained by the situation the speaker is in (Brescoll \& Uhlmann, 2008). Finally, another possibility is that testimonial injustice is less likely to occur in cases in which the person attributing credibility has nothing at stake. Although the speakers in our vignettes are personally involved in the depicted situation, participants in the study are arguably not. Thus, it is possible that in order for people to give less credibility to women speakers, they should have something at stake. Further empirical studies should test these hypotheses by (1) sampling different populations, (2) using vignettes depicting different, non-emotional situations, and (3) using different experimental designs, e.g. economic games. It is important to note that, by introducing

\footnotetext{
${ }^{7}$ We are grateful to one anonymous reviewer of this journal for these interesting suggestions.
} 
non-epistemic factors other than the social identity of the target as the determinants of testimonial injustices, these investigations could change our current understanding of this phenomenon.

We hope that our studies here pave the way for further empirical studies testing the phenomenon of testimonial injustice in a context-sensitive way, in order to have a better understanding of the conditions in which testimonial injustices are likely to happen. Studies such as the ones suggested above could not only inform our theories regarding testimonial injustices, but also provide a valuable source of information to develop interventions and socio-political strategies to prevent this type of discrimination. To conclude, we would like to stress that, as we have seen at the beginning of this paper, building on extant psychological research to defend new philosophical claims is likely to face limitations. We hope to encourage philosophers to engage in empirical research and collaborate with social scientists in order to make conceptually informed experiments that could in turn inform new conceptual developments.

\section{References}

Andersson, L. M., and Pearson, C. M. (1999). Tit for Tat? The Spiraling in the Workplace Incivility. Acad. Manag. Rev. 24, 452-471. doi:10.2307/259136.

Andrews, K. (2008). It's in your nature: A pluralistic folk psychology. Synthese 165, 13-29. doi:10.1007/s11229-007-9230-5.

Ayala, S. (2016). Speech affordances: A structural take on how much we can do with our words. European Journal of Philosophy, 24(4): 879-891.

Ayala, S. (2018). “A structural explanation of injustice in conversations: it's about norms". Pacific Philosophical Quarterly 99: 726-748

Banaji, M. R., Nosek, B. A., and Greenwald, A. G. (2015). Statistically small effects of the implicit association test can have societally large effects. J. Pers. Soc. Psychol. 108, 553-561. doi:10.1037/pspa0000016.

Barrett, L. F., and Bliss-Moreau, E. (2009). She's Emotional. He’s Having a Bad Day: Attributional Explanations for Emotion Stereotypes. Emotion 9, 649-658. 
doi:10.1037/a0016821.

Brescoll, V. L., and Uhlmann, E. L. (2008). Can an Angry Woman Get Ahead? Psychol. Sci. 19, 268-275. doi:10.1111/j.1467-9280.2008.02079.x.

Buckwalter, W. (2018). Epistemic injustice in social cognition. Australasian Journal of Philosophy, doi:10.1080/00048402.2018.1459754.

Burroughs, M. and Tollefsen, D. (2016). Learning to listen: epistemic injustice and the child. Episteme, 13(3): 359-377.

Cameron, C. D., Brown-Iannuzzi, J. L., and Payne, B. K. (2012). Sequential Priming Measures of Implicit Social Cognition. Personal. Soc. Psychol. Rev. 16, 330-350. doi:10.1177/1088868312440047.

Carlsson, R., and Agerström, J. (2016). A closer look at the discrimination outcomes in the IAT literature. Scand. J. Psychol. 57, 278-287. doi:10.1111/sjop.12288.

Cortina, L. M., Kabat-Farr, D., Leskinen, E. A., Huerta, M., and Magley, V. J. (2013). Selective Incivility as Modern Discrimination in Organizations: Evidence and Impact. $J$. Manage. 39, 1579-1605. doi:10.1177/0149206311418835.

Cortina, L. M., Magley, V. J., Williams, J. H., and Langhout, R. D. (2001). Incivility in the workplace: incidence and impact. J. Occup. Health Psychol. 6, 64-80. doi:10.1037//1076-8998.6.1.64.

Cuddy, A. J. C., Fiske, S. T., and Glick, P. (2004). When Professionals Become Mothers, Warmth Doesn't Cut the Ice. J. Soc. Issues 60, 701-718.

Cuddy, A. J. C., Fiske, S. T., Kwan, V. S. Y., Glick, P., Demoulin, S., Leyens, J. P., et al. (2009). Stereotype content model across cultures: Towards universal similarities and some differences. Br. J. Soc. Psychol. 48, 1-33. doi:10.1348/014466608X314935.

Dotson, K. (2011). Tracking Epistemic Violence, Tracking Practices of Silencing, Hypatia 26(2): $236-57$.

Eaton, A. A., Saunders, J. F., Jacobson, R. K., and West, K. (2019). How Gender and Race Stereotypes Impact the Advancement of Scholars in STEM: Professors' Biased Evaluations of Physics and Biology Post-Doctoral Candidates. Sex Roles, 1-15. doi:10.1007/s11199-019-01052-w.

Eckes, T. (2002). Paternalistic and envious gender stereotypes: Testing predictions from the stereotype content model. Sex Roles 47, 99-114. doi:10.1023/A:1021020920715. 
Fiske, S. T., Cuddy, A. J. C., Glick, P., and Xu, J. (2002). A model of (often mixed) stereotype content: Competence and warmth respectively follow from perceived status and competition. J. Pers. Soc. Psychol. 82, 878-902. doi:10.4324/9781315187280.

Fiske, S. T., Xu, J., Cuddy, A. C., and Glick, P. (1999). (Dis)respecting versus (Dis)liking: Status and interdependence predict ambivalent stereotypes of competence and warmth. J. Soc. Issues 55, 473-489. doi:10.1111/0022-4537.00128.

Forscher, P. S., Lai, C. K., Axt, J. R., Ebersole, C. R., Herman, M., Devine, P. G., et al. (2019). A Meta-Analysis of Procedures to Change Implicit Measures April. J. Pers. Soc. Psychol.

Foschi, M. (1996). Double Standards in the Evaluation of Men and Women Author ( s ): Martha Foschi Source : Social Psychology Quarterly, Vol .59, No . 3 , Special Issue : Gender and Social Published by : American Sociological Association Stable URL : http://www.jstor.org. 59, 237-254.

Foschi, M. (1994). Gender and Double Standards in the Assessment of Job Applicants Authors ( s ): Martha Foschi , Larissa Lai and Kirsten Sigerson Source : Social Psychology Quarterly, Vol . 57 , No . 4 ( Dec ., 1994 ), pp . 326-339 Published by : American Sociological Ass. 57, 326-339.

Fricker, M. (2007). Epistemic Injustice. Power and the Ethics of Knowing. Oxford: Oxford University Press.

Hauser, D. J., and Schwarz, N. (2015). Attentive Turkers: MTurk participants perform better on online attention checks than do subject pool participants. Behav. Res. Methods 41, 400-407. doi:10.3758/s13428-015-0578-z.

Hetherington, M. J., and Rudolph, T. J. (2015). Why Washington won't work: polarization, political trust, and the governing crisis. Chicago: University of Chicago Press doi:10.5860/choice.194934.

Kidd, I.J., J. Medina and G. Pohlhaus Jr. (2017), The Routledge Handbook of Epistemic Injustice. London: Routledge.

Kukla, R. (2014). Performative Force, Convention, and Discursive Injustice. Hypatia, 29(2): $440-457$.

Kurdi, B., Seitchik, A. E., Axt, J., Carroll, T., Karapetyan, A., Kaushik, N., et al. (2018). Relationship between the Implicit Association Test and intergroup behavior: A meta- 
analysis. doi:none.

Livingston, Robert W., Ashleigh Shelby Rosette, and Ella F. Washington. (2012). Can an Agentic Black Woman Get Ahead? The Impact of Race and Interpersonal Dominance on Perceptions of Female Leaders. Psychological Science, 23(4), 354-358. https://doi.org/10.1177/0956797611428079

Medina, J. (2013). The Epistemology of Resistance: Gender and Racial Oppression, Epistemic Injustice, and the Social Imagination. Oxford: Oxford University Press. Munroe, W. (2016). Testimonial Injustice and Prescriptive Credibility Deficit. Canadian Journal of Philosophy. doi:10.1080/00455091.2016.1206791.

Oswald, F. L., Mitchell, G., Blanton, H., Jaccard, J., and Tetlock, P. E. (2013). Predicting ethnic and racial discrimination: A meta-analysis of IAT criterion studies. J. Pers. Soc. Psychol. 105, 171-192. doi:10.1037/a0032734.

Oswald, F. L., Mitchell, G., Blanton, H., Jaccard, J., Tetlock, P. E., and Hart Blanton, or (2015). Using the IAT to Predict Ethnic and Racial Discrimination: Small Effect Sizes of Unknown Societal Significance. J. Pers. Soc. Psychol. 108, 562-571. doi:10.1037/pspa0000023.

Peet, A. (2015). Epistemic injustice in utterance interpretation. Synthese, 194(9): 3421-3443.

Plant, E. A., Hyde, J. S., Keltner, D., and Devine, P. G. (2000). The Gender Stereotyping of Emotions. Psychol. Women Q. 24, 81-92.

Saegert, S. (2019). Epistemological and other injustices. Social and Personality Psychology Compass. doi:10.1111/spc3.12467.

Saul, J. (2017). Implicit bias, stereotype threat, and epistemic injustice. Routledge Handb. Epistemic Injustice, 235-242. doi:10.4324/9781315212043.

Simmons, J. P., Nelson, L. D., and Simonsohn, U. (2018). False-Positive Citations. Perspect. Psychol. Sci. 13, 255-259. doi:10.1177/1745691617698146.

Spaulding, S. (2018a). Mindreading beyond belief: A more comprehensive conception of how we understand others. Philos. Compass 13, 1-11. doi:10.1111/phc3.12526.

Spaulding, S. (2018b). How we understand others. Philosophy and social cognition. NY: Routledge.

Stewart, N., Chandler, J., and Paolacci, G. (2017). Crowdsourcing Samples in Cognitive 
Science. Trends Cogn. Sci. 21, 736-748. doi:10.1016/j.tics.2017.06.007.

Traister, R. (2018). Good and Mad: The Revolutionary Power of Women's Anger. New York, NY: Simon \& Schuster.

Westra, E. (2017). Stereotypes, theory of mind, and the action-prediction hierarchy. Synthese, 1-26. doi:10.1007/s11229-017-1575-9.

Zammuner, V. L. (2000). "Men's and women's lay theories of emotion," in Gender and Emotion: Social Psychological Perspectives, ed. A. H. Fischer (Cambridge: Cambridge University Press), 48-70.

Zitelny, H., Shalom, M., and Bar-Anan, Y. (2017). What Is the Implicit Gender-Science Stereotype? Exploring Correlations Between the Gender-Science IAT and Self-Report Measures. Soc. Psychol. Personal. Sci. 8, 719-735. doi:10.1177/1948550616683017. 


\section{Appendix}

Study 1. Vignette 1, Woman.

Sarah is a 40-year-old woman who has commissioned a company to renovate the exterior of her house. While the renovation is being carried out, Sarah spends a few days away. When she returns to her house to see how the work has developed, Sarah says the following:

"The work they have done is very unprofessional. You can see right away that there are numerous errors. The exterior looked better before."

Study 1. Vignette 1, Man

Tom is a 40-year-old man who has commissioned a company to renovate the exterior of his house. While the renovation is being carried out, Tom spends a few days away. When he returns to his house to see how the work has developed, Tom says the following:

"The work they have done is very unprofessional. At first glance you can see that there are numerous errors. The exterior looked better before."

\section{Study 1. Vignette 2, Woman}

Susan is a philosophy professor at the University of Texas. Today she is attending a conference where an important professor will give a lecture on the nature of value. Susan disagrees with the theory presented at the conference. During the $Q \& A$, Susan says the following:

"The arguments that have been presented in the talk are circular. They just assume that the theory is true. Thus, they cannot prove whether this is actually the case or not."

Study 1. Vignette 2, Man

Michael is a philosophy professor at the University of Texas. Today he is attending a conference where an important professor will give a lecture on the nature of value. Michael disagrees with the theory presented at the conference. During the $Q \& A$, Michael says the following: 
"The arguments that have been presented in the talk are circular. They just assume that the theory is true. Thus, they cannot prove whether this is actually the case or not."

Study 1. Vignette 3, Woman

During a university class, students watch a video clip projected on the board. In this video there is a sequence in which a person who travels in a train refuses to sit next to another person because he is African-American. When the video screening ends, Taylor, an African American woman, says the following:

"What we have seen in the video is unacceptable. In a democratic society, we should have measures in place to avoid things like this from happening."

Study 1. Vignette 3, Man

During a university class, students watch a video clip projected on the board. In this video there is a sequence in which a person who travels in a train refuses to sit next to another person because he is African-American. When the video screening ends, David, an African American man, says the following:

"What we have seen in the video is unacceptable. In a democratic society, we should have measures in place to avoid things like this from happening."

Study 1 . Vignette 4 , Woman

The members of the Supreme Court have chosen an image of a naked woman as a poster to announce an event. Lisa, a female magistrate, sends a statement to the Supreme Court saying the following:

"This image could be appropriate for an artistic exhibition, but not in this context. The figure of a naked woman is no longer the way society represents justice since centuries ago."

Study 1. Vignette 4, Man

The members of the Supreme Court have chosen an image of a naked woman as a poster to announce an event. Mark, a male magistrate, sends a statement to the Supreme Court saying the following: 
"This image could be appropriate for an artistic exhibition, but not in this context. The figure of a naked woman is no longer the way society represents justice since centuries ago."

Study 2. Vignette 1, Woman

Sarah is a 40-year-old woman who has commissioned a company to renovate the exterior of her house. She selected the company because it had very good reviews online. While the renovation is being carried out, Sarah spends a few days away. When she returns to her house to see how the work has developed, Sarah says the following:

"The work they have done is very unprofessional. You can see right away that there are numerous errors. The exterior looked better before."

Study 2. Vignette 1, Man

Tom is a 40-year-old man who has commissioned a company to renovate the exterior of his house. He selected the company because it had very good reviews online. While the renovation is being carried out, Tom spends a few days away. When he returns to his house to see how the work has developed, Tom says the following:

"The work they have done is very unprofessional. At first glance you can see that there are numerous errors. The exterior looked better before."

Study 2. Vignette 2, Woman

Susan is a philosophy professor at the University of Texas. Today she is attending a conference where another professor will give a lecture on the nature of value. The theory that this professor presents is very influential and well-regarded, but Susan disagrees with it. During the $Q \& A$, Susan says the following:

"The arguments that have been presented in the talk are circular. They just assume that the theory is true. Thus, they cannot prove whether this is actually the case or not."

Study 2. Vignette 2, Man

Michael is a philosophy professor at the University of Texas. Today he is attending a conference where an important professor will give a lecture on the nature of value. The theory 
that this professor presents is very influential and well-regarded, but Michael disagrees with it. During the $Q \& A$, Michael says the following:

"The arguments that have been presented in the talk are circular. They just assume that the theory is true. Thus, they cannot prove whether this is actually the case or not."

Study 2. Vignette 3, Woman

Linda is a 30-year-old woman. Two weeks ago, her husband mysteriously disappeared. Today, Linda receives a call from the police office. They communicate that they have not found her husband, but they have clear indications that he committed suicide. Linda replies:

"That is just false. It's completely impossible. He would never commit suicide. He was a very happy man."

Study 2. Vignette 3, Man

Daniel is a 30-year-old man. Two weeks ago, his wife mysteriously disappeared.Today, Daniel receives a call from the police office. They communicate that they have not found his wife, but they have clear indications that she committed suicide. Daniel replies:

"That is just false. It's completely impossible. She would never commit suicide. She was a very happy woman."

Study 2. Vignette 4, Woman

Lisa works in the communications department at a company. The company has hired a very well-regarded consulting agency to get their advice regarding the company finances. The consulting agency advises to cut the budget for the communications department. When discussing this measure at the company meeting, Lisa says:

"Implementing this measure is a mistake. The numbers show that the communications department has done a crucial job for the success of this company."

Study 2. Vignette 4, Man 
Mark works in the communications department at a company. The company has hired a very well-regarded consulting agency to get their advice regarding the company finances. The consulting agency advises to cut the budget for the communications department. When discussing this measure at the company meeting, Mark says:

"Implementing this measure is a mistake. The numbers show that the communications department has done a crucial job for the success of this company." 